\title{
Effects of a Reading Strategy Training Aimed at Improving Mental Simulation in Primary School Children
}

\author{
Björn B. de Koning ${ }^{1,2} \cdot$ Lisanne T. Bos ${ }^{2}$. \\ Stephanie I. Wassenburg ${ }^{2}$ Menno van der $\operatorname{Schoot}^{2}$
}

(C) The Author(s) 2016. This article is published with open access at Springerlink.com

\begin{abstract}
This study investigated the effects of a mental simulation training targeted at improving children's reading comprehension. In a 4-week period, one group of third and fourth graders $(n=75)$ learned to draw upon their sensorimotor memories and experiences to mentally simulate text (experimental training group), whereas another group $(n=51)$ received the schools' regular reading comprehension instructions (control training group). Pre-toposttest differences in general reading comprehension, reading motivation, and mental simulation (distinguishing between perceptual and motor simulation) were examined to evaluate the trainings' effectiveness. Compared to the control group, children who had received the mental simulation training showed improved performance on general reading comprehension (in Grade 3) and scored higher on reading motivation (in Grades 3 and 4). There were no performance differences between groups on the mental simulation measures. These findings indicate that it is beneficial for children to encourage and teach them to connect their sensorimotor experiences to the text they are reading.
\end{abstract}

Keywords Reading comprehension - Mental simulation - Intervention · Primary school children · Embodied cognition

Reading comprehension research generally assumes that comprehension of a stretch of text involves the construction of a mental representation of the state-of-affairs described in a text, a

Björn B. de Koning

b.b.dekoning@ fsw.eur.nl

1 Department of Psychology, Education, and Child Studies, Erasmus School of Behavioral and Social Sciences, Erasmus University Rotterdam, Burgemeester Oudlaan 50, 3062 PA Rotterdam,

The Netherlands

2 Department of Pedagogical and Educational Sciences, Section Educational Neuroscience, Faculty of Behavioral and Movement Sciences and LEARN! Institute, Vrije Universiteit Amsterdam, van der Boechorststraat 1, 1081 BT Amsterdam, The Netherlands 
situation model, rather than of the text itself (Kintsch 1988; Kintsch and van Dijk 1978; Zwaan and Radvansky 1998). According to situation model theories such as the event-indexing model (Zwaan et al. 1995) and the construction-integration model (Kintsch 1988), situation models are constructed, and continuously updated, based on information that is presented in a story and/or reader's knowledge of the world along multiple dimensions: character, time, space, intentionality, and causation. Over the years, complementary insights on situation models have been provided by embodied theories of language comprehension (Barsalou 1999; Fischer and Zwaan 2008; Glenberg 1997). Perhaps the most influential one has been that the representations of the various situation model dimensions are (partially) based on (re)activations of brain areas governing analogous perception and action in the real world (Barsalou 2008; for an extended discussion on the interplay between symbolic and sensorimotor representations, see Zwaan 2015). Accordingly, it has been proposed that understanding text involves a mental simulation of described events by reactivating and integrating traces of earlier experiences from multiple perceptual and motor modalities in the brain that were recruited when the actual experience was acquired (Barsalou 1999). Readers who mentally simulate the story's perceptual and motoric elements incorporating them into their evolving "embodied situation model" (Glenberg 1999) are assumed to build a deeper understanding of a text (for an overview, see Meteyard et al. 2012).

So far, these recent insights have not yet found their way into the actual classroom practice of reading comprehension instruction. More specifically, it is currently unclear whether it is possible to teach children mental simulation skills and to what extent such instructions are associated with improved text comprehension. Filling this gap provides an opportunity to help children to become better text comprehenders, counteracting the worldwide expressed concern that a significant number of primary school children fail to attain a sufficient level of reading comprehension. For example, The National Center for Education Statistics (2011) reported that $33 \%$ of fourth-grade students and $24 \%$ of eighth-grade students in the USA are performing below basic standards. Periodic surveys of reading comprehension in the Netherlands have shown similar results (van Berkel et al. 2007; van der Schoot 2008). In response to these issues, the present study sets out to demonstrate that a training aimed at the re-enactment of perceptual and motor experiences when constructing a situation model during reading is capable of supporting children's general reading comprehension performance. It should be mentioned that this training was part of a broader large-scale reading comprehension intervention aimed at teaching children to (more effectively) construct a situation model from text. The other two situation model strategy trainings developed within this intervention (i.e. inference making and comprehension monitoring) are described and discussed in more detail in Bos et al. (2016) and Wassenburg et al. (2015a), respectively. In the present paper, we only report the aim, content, and outcomes of the "mental simulation training".

\section{Mental Simulation as a Means to Support Reading Comprehension}

By now, a wealth of behavioral (Louwerse et al. 2015) and neuroimaging (Kiefer and Pulvermüller 2012) evidence has accumulated demonstrating that reading comprehension involves the re-enactment of sensorimotor experiences, not only when processing individual words or sentences but also during comprehension of discourse (e.g., Nijhof and Willems 2015). Conceivably, in taking this a step further towards a mental simulation training, there are several ways to involve readers' sensorimotor experiences when processing text. According to 
De Koning and van der Schoot $(2013,2014)$ readers have at least two possibilities to connect sensorimotor experiences to text content: (1) reactivating one's privately stored sensorimotor experiences relevant to the story and tying these to the situation described in a text and (2) endowing readers with relevant sensorimotor experiences during reading such as when actually "acting out" a story using toy figures or imagining doing so, which has been associated with improved memory for and comprehension of the text (Berenhaus et al. 2015; Glenberg 2011; Glenberg et al. 2004). In the present study, the first one of these possibilities will be investigated as it has not yet received systematic attention from researchers (De Koning and van der Schoot 2013). That is, we aim to encourage children inexperienced in constructing an embodied situation model to draw upon their sensory and motor experiences during reading. Retrieving these experiences, which involves the integration of neural patterns corresponding to prior perceptions with the events and object mentioned in the text, enables readers to simulate the situation described in the text as vividly as possible (Barsalou 2008; De Koning and van der Schoot 2013). Doing so, readers place themselves mentally in the shoes of the story's main character and use their multisensory experiences to simulate the described scenario as if they were actually experiencing the story (Zwaan 2004). In other words, readers engage in an "emulative mental simulation" in which the simulated psychological, perceptual, and motoric processes mimic those involved in the simulated event (Moulton and Kosslyn 2009). According to Moulton and Kosslyn (2009, also for a more extended discussion on this issue), mental imagery plays a key role in emulative mental simulations: "One uses imagery to simulate what one would perceive if one were in a specific situation; this is as true of imagery used to retrieve memories as it is of imagery used to predict the future." (p. 1278). So, if imagery is used, which not necessarily occurs in all emulative simulations, it is used in service of mental simulation. This provides a more comprehensive view of mental simulation compared to initial conceptions of mental simulation where a clear distinction is drawn between imagery and simulation, and one remains silent about their interplay. While in these conceptions imagery is typically associated with deliberate, conscious attempts to construct a mental representation, simulation is assumed to involve automatic, unconscious processing (e.g., Barsalou 2008; Kent and Lamberts 2008; Trumpp et al. 2013, 2014). Our intention within the present study is to explore whether mental simulation via imagery can be supported as a means to enhance reading comprehension. That is, we investigate the extent to which making children aware of the importance of connecting their perceptual and motor experiences to the text content and teaching them how to do so helps them to mentally simulate the described situation, and ultimately improve their reading comprehension performance.

\section{Mental Simulation Training}

The training developed for this study consists of three parts. The first part works towards the construction of a multisensory representation of the situation described in a text. Essentially, children were made aware that they can use more than just their visual sense to represent the described situation. Encouraging and supporting children to also pay attention to the sounds, smells, tastes, movements, and emotions that can be experienced in the described situation in order to incorporate these experiences into a simulation of the text content has both practical and theoretical value. In reading comprehension instruction, teachers typically ask children to represent text content only visually and thus leave potential benefits of incorporating other sensory modalities unexploited (De Koning and van der Schoot 2014; van de Ven 2009). 
Additionally, research on stimulating mental simulation processes is scarce and lacks systematic studies particularly on how to support readers to connect experiences from multiple sensory modalities to a text (De Koning and van der Schoot 2013).

The second and third part of the training zoom in on stimulating visual simulation (second part) and motor simulation (third part). The present study contributes to existing work on (supporting) imagery and mental simulation in an important way. Rather than requiring readers to just represent described objects and events, we paid particular attention to the fact that information that is relevant to accurately mentally represent the objects and events contained in a story is often not explicitly described. This was inspired by more fundamental embodied cognition research showing that mental simulations of objects and events are dependent upon the perceptual object features (Zwaan and Pecher 2012) and motor movements (Glenberg and Kaschak 2002) that are implicitly described in a sentence. For example, using the sentencepicture verification paradigm, Engelen et al. (2011) presented participants with sentences implying a particular object shape such as "The man saw the egg in the skillet". After reading each sentence, participants had to verify whether a pictured object, which either matched (egg sunny-side up) or mismatched (whole egg) the shape implied in the sentence, had been mentioned in the preceding sentence. Readers verified pictures faster when they matched rather than mismatched the perceptual information from the preceding sentence This so-called match advantage has by now been found for multiple perceptual object features such as shape, orientation, color, and size (De Koning et al. 2016; for a review, see Horchak et al. 2014).

Similar findings showing a match advantage have been obtained for motor simulations (e.g., Bergen and Wheeler 2010; Gianelli et al. 2011; Glenberg and Kaschak 2002). Using a sentence-sensibility judgment task, Glenberg and Kaschak (2002), for example, asked readers to read meaningful sentences implying either a movement towards (e.g., "He opens de drawer") or away ("He closes the drawer") from the body or nonsense sentences (e.g., "He boils the air"). In judging whether a sentence is meaningful, participants had to move their arm forward (away from the body) or backward (towards the body) to push the response button, creating a match (backward arm movement for the sentence "He opens the drawer") or mismatch (forward movement for the sentence "He opens the drawer") with the movement implied in the sentence. Results showed an action-sentence compatibility effect meaning that participants were faster to verify whether a sentence was meaningful or not when the direction of movement implied in the sentence matched the movement that was required for responding. Together, the above studies have been taken to suggest that perceptual simulations and motor simulations are sensitive to the way objects and events are described. Making readers aware of these subtle differences when teaching them to simulate perceptual and motor information described in a text thus seems relevant. Therefore, we addressed this in our training program, that is, we taught readers how they could make use of words or phrases in the text to enable them to incorporate the objects and events into their mental simulation in a way that mimics the described situation.

\section{Evaluation of the Training's Effectiveness}

So, our training program was developed to enhance children's mental simulation skills contributing to an embodied situation model and hence deeper comprehension of text. In evaluating the effectiveness of our training program, we considered three aspects. First, we examined readers' performance on a standardized general reading comprehension assessment. 
We anticipated the mental simulation training to result in higher pre-to-posttest improvements on general reading comprehension. This expectation is based on the fact that having received explicit instruction on mental simulation, readers are more likely to connect the described situation to their own sensorimotor experiences and hence create a richer multisensory simulation that is associated with deeper comprehension. As our training aimed to equip readers with the necessary "cognitive tools" to embody text contents in general, it is likely that performance on measures of general text comprehension improves. To the best of our knowledge, this would provide the first evidence for the beneficial effect of a mental simulation training that encourages children to draw upon their sensorimotor experiences on general reading comprehension.

Second, we explored the possibility that our mental simulation training would impact reading motivation. In particular, children may develop a more positive attitude towards reading comprehension after the training than they had before because the training particularly required children to draw upon their own experiences to simulate the text as if actually being part of the story. From research on the interplay between motivation and reading (comprehension), it is known that children who connect their own knowledge and experiences to the information in a text, build a richer and more vivid mental representation of the text, which in turn, leads to increased motivation to read (e.g. Retelsdorf et al. 2011; Taboada et al. 2009; Van Sluys 2008). Noticeably, such an improvement of reading motivation would be specifically desirable because of its bidirectional relation with reading comprehension, which was previously shown by numerous studies involving primary school children (for an overview see Morgan and Fuchs 2007).

Third, we looked in more detail at training-related changes in readers' mental simulation skills. To keep a close link with the more fundamental research on mental simulation, we administered two (aforementioned) tasks that are well-known and frequently used for measuring perceptual simulation and motor simulation: the sentence-picture verification task (e.g., Engelen et al. 2011) and the sentence-sensibility judgment task (Glenberg and Kaschak 2002). If our training helps children to become more sensitive to implicitly described perceptual and motor information, this should be reflected in the magnitude of the match advantage in these two tasks. Children who have practiced mentally simulating implied perceptual and motor information in a text are likely to indicate faster whether this (re)activated perceptual and motor information overlaps with visually depicted objects (SPVT) and actual physical (direction of) movements (SSJT). Consequently, after the training these children are expected to produce a stronger match advantage than children who did not receive this training.

\section{Method}

\section{Participants}

Participants were 143 third and fourth graders from five regular primary schools in a large urban area in the Netherlands. They were recruited as part of a larger reading comprehension intervention (as mentioned in the Introduction) wherein at the same time other children from the same schools received training in inference making skills (Bos et al. 2016) and comprehension monitoring strategies (Wassenburg et al. 2015a). The schools where this intervention study was conducted had a general cooperation agreement with the university, but they voluntarily participated in this study. In accordance with a procedure preferred by the schools 
and endorsed by the ethical committee of the faculty, a letter describing the aim and methods of the study was provided to the children's parents. Parents could allow or deny the participation of their child by returning a preprinted objection/permission note. Informed consent was obtained for all individual participants included in the study.

Children with dyslexia and/or an IQ less than 85 , as indicated by school records, were excluded. Also children for which school records revealed (diagnosed) problems, indicating developmental or intellectual disadvantages, were excluded from the study. This resulted in removal of 17 children from the initial sample. Of the remaining sample, 75 children participated in the mental simulation training group and 51 children participated in the control training group (this control group was also used in Bos et al. 2016 and Wassenburg et al. 2015a).

Practical and organizational reasons imposed by the schools made it impossible to randomly assign children to training groups. For example, schools preferred not to make withinclass divisions between groups of mental simulation training and control training children. However, after randomly assigning classes to training groups, it turned out that the two groups were comparable on age, socio-economic status (as indicated by the Dutch neighborhood level status score, which is computed from the average neighborhood income, the percentage of residents with a low income, the percentage of low educated residents, and the percentage of unemployed residents, derived from the Netherlands Institute for Social Research; Knol et al. 2012), class size, decoding skill (as indicated by raw scores on a standardized Dutch word reading test [Een Minuut Test; Brus and Voeten 1999]), and IQ (as indicated by raw scores on Raven's Standard Progressive Matrices-Short Form). Group characteristics are reported in Table 1.

\section{Design}

The study employed a pretest-posttest control group design with general reading comprehension, reading motivation, and mental simulation (i.e., visual and motor simulation as the trained reading skills) as dependent variables and training group (mental simulation training vs. control training), time (pretest vs. posttest), and Grade (3 vs. 4) as independent variables. In the 2 weeks before and after the mental simulation training, trained research assistants administered the pre- and posttests. Pre- and posttests consisted of different versions of the same tests, and the order of the tests was counterbalanced across participants.

Table 1 Characteristics of participants in the mental simulation training group and the control training group

\begin{tabular}{clll}
\hline & $\begin{array}{l}\text { Control group } \\
\text { Mean (SD) }\end{array}$ & $\begin{array}{l}\text { Training group } \\
\text { Mean (SD) }\end{array}$ & $t(\mathrm{df})$ \\
\hline Age (year/month) & $9: 8(0: 9)$ & $9: 7(0: 8)$ & $0.54(122)$ \\
Socio-economic status & $0.54(.62)$ & $0.36(0.57)$ & $1.69(123)$ \\
Class size & $26.27(4.72)$ & $26.09(0.75)$ & $0.27(51.75)$ \\
Decoding & $67.90(13.42)$ & $63.81(14.23)$ & $1.61(123)$ \\
IQ & $21.38(3.93)$ & $21.89(3.34)$ & $-0.78(122)$ \\
\hline
\end{tabular}

Age refers to children's age expressed in years and months; socio-economic status refers to children's neighborhood status score (Knol et al. 2012); class size refers to the (average) number of children in participating classes; decoding refers to technical reading skill as measured by a standardized Dutch word reading test (Een Minuut Test; Brus and Voeten 1999); IQ refers to children's intelligence quotient as indicated by raw scores on Raven's Standard Progressive Matrices-Short Form 


\section{Mental Simulation Training}

Mental simulation was taught in a 4-week training program containing eight 30-min lessons (two lessons per week). Half of the lessons were instruction lessons conducted in groups (lessons 1, 3, 5, and 7), whereas the other half were computer-based lessons conducted individually (lessons 2, 4, 6, and 8). Instruction lessons and computer-based lessons were taught alternately, so each computer-based lesson was preceded by an instruction lesson. In all lessons, we used a balanced approach of direct instruction, modeling, guided practice, and individual practice (Houtveen and van de Grift 2007). Particularly, depending on whether it involved an instruction lesson or a computer-based lesson, relatively more time was spent on direct instruction, modeling, and guided practice (in the instruction lessons) or on guided and individual practice (in the computer-based lessons). The instructional procedure and setup matched as closely as possible the control training to maximize comparability. Lessons were conducted by trained research assistants (others than those who administered the pre- and posttests) who followed standardized instructions and had received elaborate training before the start of the training phase. The eight lessons replaced the school's regular reading comprehension lessons, that is, during the 4 weeks of training children in the mental simulation training received the instruction- and computer-based lessons at the moments the children in the control group received the school's regular reading comprehension lessons (which had the same duration as the mental simulation training).

To promote children's engagement and motivation for the mental simulation training, the following measures were taken. First, the training program was presented to the children as a "movie director training" meant to teach them, among other things, how to use their senses to create a "movie from the text" in their head and experience the described events as if they were actually the main character in that "movie". Second, an abundant variety of relevant, levelappropriate, and appealing text examples was used to explain the different instructions, and guide the children in reaching the training goals. Third, we applied scaffolding techniques including (1) gradual fading of teacher support and (2) transfer of responsibility from the teacher to the students once the latter were beginning to become more competent (Guthrie et al. 2007; Houtveen and van de Grift 2007). Fourth, each lesson ended with a reflective discussion about what and how the children had learned and why that is important.

Instruction Lessons Instruction lessons were provided to groups of 5 or 6 children in a separate classroom. Rather than adopting a primarily top-bottom approach, these lessons were collaborative and interactive in nature with children in the role of engaged learners. The training aimed at teaching children why mental simulation of text content is important and how this can be done. Particularly, children learned to draw upon their own sensory and motor experiences during reading and to connect the sensorimotor information retrieved from memory to the text they were reading. The first three instruction lessons each addressed a specific aspect of mental simulation, while the fourth instruction lesson covered all of them simultaneously.

During the first instruction lesson (lesson 1), children were introduced to the idea that they can use all their senses, not just their mind's eye, to represent the events and actions that are described in a text. For example, it was explained that when reading a narrative children could place themselves in the shoes of the main character and experience all colors, sounds, smells, tastes, movements, and emotions as if they were real. For example, children were provided with a short sentence describing a situation (e.g., enjoying a day at the beach) and then had to 
describe what they "saw," "heard," "smelled," and "tasted" as well as their tactile/motoric and emotional experiences given the described situation. So, children could indicate they 'saw' the blue color of the sea, 'heard' the waves clattering when reaching the shore, 'smelled' sunscreen, 'touched' the cold sea water with their feet, and 'felt' happy. Furthermore, by discussing the provided sensorimotor experiences in relation to the sentences children learned that using these multisensory experiences to construct a mental simulation actually facilitates comprehension of the text.

The second instruction lesson (lesson 3) focused on visual simulation, more specifically on simulating the visual appearance of objects, particularly object shape, that is described in a text. Children learned that visual information about objects is often implicitly described or "hidden" in a text and were encouraged to mentally simulate this information during reading. For example, the sentence "The girl looked at the paper in the dustbin" suggests a distinct shape for the paper (i.e., that the paper is fumbled up). They practiced identifying such implicit textual cues in multi-sentence (1-3 sentences) cloze exercises that were aimed at eliciting mental simulation. As an example, children had to fill in the term referring to an object's changed shape (here: wad of paper) while reading the sentence "She grabbed the ...[fill in] out of it and threw it to her brother.", which could only be achieved if they were mentally simulating the event described in the text and use the words in the text as cues for guiding their mental simulation processes. Furthermore, it was explained that visually simulating information implicitly described in a text supports comprehension of that text.

In the third instruction lesson (lesson 5), motor simulation was addressed. Children were taught that, similar to visual information, texts also often contain "hidden" information on the direction of movement, such as in the sentence "She handed over the key to her husband.", which suggests an arm movement away from the body. From identifying the direction of movement in single sentences while actually performing the implied movement, children progressed to reading single sentences while simulating the movement in their head (without physically performing the movement), and then finally engaged in a matching exercise in which they had to indicate which of two sentences described a movement that runs in the same direction as the movement described in a target sentence. For example, children had to decide whether "You open the car door" or "You ring the doorbell" matches in terms of movement direction with the target sentence "You pull the plug out of the wall outlet". For these exercises children were instructed to mentally simulate the movement that was implied in the sentences within their head during reading. Furthermore, it was explained that simulating information about direction of movement implicitly described in a text supports comprehension of that text.

The fourth instruction lesson (lesson 7), consisted of a recapitulation of the previous instruction lessons. Rather than the trainer re-voicing the previous instructions, it was up to the children to explain to themselves and to others the aspects of mental simulation that they had learned. So, they tried to explain what multisensory, visual, and motor simulation is, how this can be achieved and why it is important to mentally simulate text this way. The main purpose of this was to ensure that the learned information became further internalized. Moreover, children learned to flexibly apply the different aspects of mental simulation to text as they simultaneously addressed and practiced with the aspects of mental simulation that they had previously encountered in isolation (1) in (intermixed) exercises similar to those in the previous lessons as well as (2) in reading of multi-sentence texts (1-4 sentences) that contained information requiring them to simulate visual, motor, and other sensory information (e.g., sound) within the same text passage. 
Computer-Based Lessons In the computer-based lessons, the above-mentioned multisensory exercises (lessons 2 and 8), cloze exercises (lessons 4 and 8), and matching exercises (lessons 6 and 8 ) were used to trigger the mental simulation processes trained in the instruction lessons. Their main purpose was to further practice with the mental simulation skills in order to automatize them. Additionally, the computer-based lessons aimed at furthering children's understanding about the importance of mental simulation. That is, these lessons extended the instruction lessons by specifically addressing how mental simulation may affect subsequent text comprehension. For example, lesson 4, targeting visual simulation, explained that visually simulating the objects in a sentence does not only result in better comprehension of that sentence, but also may help to better or faster understand the rest of the text if elsewhere in the text a reference is made to the visually simulated information. For example, for the previously mentioned "wad of paper" example, it was explained that after having mentally simulated the implied shape (i.e., wad of paper) likely facilitates reading a sentence like "The boy spread out the paper to take a final look at his failed drawing" later on in the text. The last computer-based lesson summarized what was covered in the previous lessons and consisted of a mixture of the previous exercises and used multi-sentence (1-4) texts containing to-besimulated information to support flexible application of mental simulation skills.

The computer-based lessons took place in a separate (computer) classroom and involved the same groups of 5 to 6 children from the instruction lessons. Whereas the exercises during the computer-based lessons had to be completed individually, the lessons always started and ended with a plenary discussion. Specifically, each computer-based lesson started by recapitulating what was taught in the preceding instruction lesson and ended with a discussion in which the children reflected on the what, how, and why of the strategic reading activities which were trained.

\section{Control Training}

Children in the control training group attended the school's regular reading comprehension curriculum taught by their own teachers. This meant that, similar to children in the mental simulation training group, they received reading comprehension lessons twice a week for 30 min during 4 weeks. The control training took place at the same moment as the mental simulation training and made use of one of the most popular reading comprehension methods in the Netherlands (i.e., Nieuwsbegrip). The reading lessons involved whole-class reading as well as small group reading instruction appropriate for children's reading level combined with individual practice consisting of both paper-and-pencil and computerized exercises. The reading strategies taught in these lessons included predicting, clarifying, and summarizing.

\section{Pre- and Posttests}

Children completed the reading comprehension test and the reading motivation questions in their classroom using a whole-class test taking approach. The sentence-picture verification task and the sentence-sensibility judgment task were completed individually in a silent room at the children's school.

Reading Comprehension Children's reading comprehension skills were measured with the Grade 3 and Grade 4 versions of the standardized CITO Reading Comprehension Test 
(Institute for Educational Measurement 2010). This test is part of the standard Dutch pupil monitoring system and is designed to determine general reading comprehension level in primary school children. It contains two modules, each consisting of a text and 25 multiple choice questions that had to be answered within $40 \mathrm{~min}$. The questions address the word, sentence, and text level and aim to tap the text-base level and situation model level representations which can be constructed from the text (e.g., Kintsch 1988). Students' raw test scores on the 50 items were rescaled to normed proficiency scores, enabling us to compare (1) the results of the pre- and posttest versions of the CITO Reading Comprehension Test and (2) the performance of children from different grades (i.e., Grades 3 and 4). With Cronbach's alpha's of at least 0.85 , the internal consistency coefficient of the tests was high (Feenstra et al. 2010).

Reading Motivation All participating children were asked how much they liked reading comprehension before and after the training. They answered using a 4-point Likert scale represented by cartoon figures ( $1=\mathrm{I}$ do not like it at all; $4=\mathrm{I}$ like it a lot $)$. Next, children had the opportunity to orally explain why they did or did not like reading comprehension. The oral answers were not systematically documented and hence were not taken up in the analyses. Their purpose was to provide children the opportunity to voice their opinion and express their wishes for improvement.

Sentence-Picture Verification Task Visual simulation abilities were measured using the sentence-picture verification task which was based on Zwaan et al. (2002) and Engelen et al. (2011). In this task, participants read a sentence implying a particular shape for an object and then had to indicate as fast and accurate as possible whether or not the object shown in a subsequently presented picture was mentioned in the sentence. A set of 24 sentence-picture pairs were used. Of the 24 experimental sentences, there were two versions that only differed in the shape of the object that it implied (e.g., "He saw the egg in the skillet" vs. "He saw the egg in the box"). Participants read one of the two versions of each sentence (e.g., "He saw the egg in the skillet") from the computer screen, and then were shown either a picture of the critical object that matched (e.g., egg sunnyside up) or mismatched (e.g., round egg) the shape implied in the sentence. All pictures were colored drawings created by a professional draftsman and were scaled to occupy an area of approximately $15 \times 15 \mathrm{~cm}$ on the computer screen.

The two versions of experimental sentences and the two versions of pictures were arranged in four material sets using a Latin square. This ensured that each sentence-picture combination appeared equally often in all conditions (i.e., match vs. mismatch) across participants. Each participant saw just one of these sets. In each set, half of the experimental sentence-picture items matched whereas the other half mismatched in object shape. All experimental items required a yes response. To balance the number of yes/no responses, 24 filler items, which always required a no response, were added to each material set. Filler trials consisted of a sentence, similarly structured as experimental sentences, followed by a picture of an object that was not mentioned in the preceding sentence (e.g., the sentence "The girl put the ring on her finger" followed by a picture of a garbage bin).

The sentence-picture verification task started with two practice trials to familiarize children with the task. For incorrect answers, the test leader explained why the answer they had chosen was wrong. On subsequent experimental trials, no feedback nor explanations were provided. The task lasted approximately $10 \mathrm{~min}$. The internal consistency of this test was high with a Cronbach's alpha of 0.85 and 0.92 in the pretest and posttest, respectively. 
Sentence-Sensibility Judgment Task Motor simulation abilities were measured using the sentence-sensibility judgment task which was based on, among others, Glenberg and Kaschak (2002). In this task, participants read sentences that implicitly described a movement towards (e.g., "You opened the drawer") or away (e.g., "You closed the drawer") from the body. For each sentence, participants indicated as fast and accurate as possible whether the sentence was sensible (like the above sentences) or not. A total of 48 experimental sentences were used, of which half implied a movement towards the body and the other half implied a movement away from the body. Experimental sentences always required a yes response. Each sentence had a towards (e.g., "You grab the paper from the mailbox") and an away ("You put the paper in the mailbox") version. Experimental, as well as nonsense, sentences always were of the format "You - Verb - Object." Nonsense sentences, such as "You boiled the air," did not imply any direction of movement and always required a no response. These sentences (an equal number as the experimental sentences) thus served as fillers to balance yes/no responses. As we had two sentence versions (away vs. towards) and two response directions (away vs. towards; see below), we created four material sets using a Latin square, similar to how this was done in the sentence-picture verification task.

Following Glenberg and Kaschak (2002), sensibility judgments on the sentences were given on a button box $(28 \times 16 \times 6 \mathrm{~cm})$. The button box was placed vertically on the table between the participant and the computer screen, that is, with the longest dimension projecting towards the computer screen. The button box contained three buttons that, with this placement of the button box, were near, middle, or far from the participant's body. On each trial, visual presentation of the sentence was initiated by pressing and holding the middle button with the right hand index finger. The sentence was displayed as long as the middle button was held, until the participant had decided whether the sentence was sensible or not, whereupon they released the middle button and pressed the button labeled "yes - sensible" or "no - nonsense." The "yes - sensible" button was always the farthest away from the participant's body and thus required a movement away from the body (i.e., forward movement from the middle button). The "no - nonsense" button was always closest to the participant's body and thus required a movement towards the body (i.e., backward movement from the middle button). Given that half of the experimental (i.e., sensible) sentences matched the response direction (the sentence implies movement away from the body and so does the required (yes) response direction) while the other half mismatched the response direction (the sentence implies movement towards the body whereas the yes response required a movement in the opposite direction), it is possible to compare the responses on the matching and mismatching trials. In order to determine such a match effect, or the so-called Action-Sentence Compatibility Effect (ACE), in line with Glenberg and Kaschak (2002), we examined the time it took participants to read the sentence and then release the middle button. This measure has been particularly associated with motor simulation of sentences describing action performed by you (see Bergen and Wheeler 2010). Given that this match advantage does not vary depending on whether a "yes"/ "no" response requires a towards or away movement (Glenberg and Kaschak 2002), for reasons of parsimony, we decided to only ask participants to make "yes" responses using an away movement and "no" responses using a towards movement. The sentence-sensibility judgment task started with two practice trials to familiarize children with the task. For incorrect answers, the test leader explained why the answer they had chosen was wrong. On subsequent experimental trials, no feedback nor explanations were provided. The task lasted approximately $10 \mathrm{~min}$. The internal consistency of this test was medium (Cronbach's alpha $=0.75$ ) at pretest and high (Cronbach's alpha $=0.75)$ at posttest. 


\section{Results}

\section{Reading Comprehension and Reading Motivation}

Regarding reading comprehension, a significant improvement was observed in children's general reading comprehension performance due to the mental simulation training. In particular, as can be seen in Fig. 1, children who had received the mental simulation training showed a larger improvement on the CITO Standardized Reading Comprehension Test than those in the control training group. An overall $2 \times 2 \times 2$ analysis of variance (ANOVA) on the reading comprehension proficiency scores with time (pretest vs. posttest) as within-subject factor and training group (mental simulation vs. control) and grade (Grade 3 vs. Grade 4$)$ as between-subject factors confirmed this pattern. Specifically, the training group $\times$ time interaction was significant $\left(F(1,92)=5.12, p=0.03, \eta_{p}{ }^{2}=0.05\right)$, and this interaction appeared to vary as a function of grade $\left(F(1,92)=4.55, p=0.04 . \eta_{p}{ }^{2}=0.05\right)$. In Grade 3 , there was a significant training group $\times$ time interaction $\left(F(1,30)=6.60, p=0.02, \eta_{p}{ }^{2}=0.18\right)$; but in Grade 4 , this interaction was not significant $\left(F(1,62)=0.13, p=0.91, \eta_{p}{ }^{2}=0.00\right)$. To further elucidate this pattern of findings, we investigated (1) for each grade the differences in reading comprehension gains in the experimental and control training groups and (2) for each of the training groups the pretest-posttest differences in reading comprehension scores. Analysis of the gain scores showed that third graders in the mental simulation training showed a larger gain in reading comprehension scores than third graders in the control training group $(t(30)=0.14$, $p=0.01$ ), whereas fourth graders' reading comprehension gains were statistically comparable in the mental simulation training group and the control training group $(t(62)=0.12, p=0.45)$. The analysis of the second aspect revealed that the mental simulation training group showed a significant pre-to-posttest improvement in reading comprehension scores for children in Grade $3(t(19)=1.82, p=0.04)$ while the control training group children in Grade 3 showed a significant pre-to-posttest decline in their reading comprehension performance $(t(1)=2.34, p=0.02)$. In the mental simulation training group, also a pre-to-posttest improvement in reading comprehension scores was observed for children Grade $4(t(26)=4.07, p=0.00)$, but a similar improvement was seen for Grade 4 children in the control training group $(t(36)=2.56, p=0.01)$.

Furthermore, the gains in general reading comprehension found for the mental simulation training group were accompanied by higher levels of reading motivation. As shown in Fig. 2, children in the mental simulation training group (time $F(1,45)=36.04$, $p<0.001, \eta_{p}{ }^{2}=0.43$ ), but not those in the control training group (time $F(1,47)=0.02$, $p=0.89, \eta_{p}{ }^{2}=0.00$ ), indicated that they enjoy reading more after the training than they did before the training. An ANOVA (with the above factors) on the motivation data confirms this in a significant training group $\times$ time interaction $(F(1,94)=15.46, p<0.001$, $\eta_{p}{ }^{2}=0.14$ ). There was no effect of grade on these reading motivation scores (grade $F(1,94)=0.98, p=0.32, \eta_{p}{ }^{2}=0.01 ;$ training group $\times$ time $\times$ grade $F(1,94)=1.39$, $\left.p=0.24, \eta_{p}{ }^{2}=0.02\right)$. So, higher levels of reading motivation were reported by children in Grade $3\left(M_{\text {pretest }}=2.24, \mathrm{SD}_{\text {pretest }}=1.14 ; M_{\text {posttest }}=3.43, \mathrm{SD}_{\text {posttest }}=0.60\right)$ and Grade 4 $\left(M_{\text {pretest }}=2.11, \mathrm{SD}_{\text {pretest }}=1.03 ; M_{\text {posttest }}=2.93, \mathrm{SD}_{\text {posttest }}=1.15\right)$ who had followed the mental simulation training group but not by third graders $\left(M_{\text {pretest }}=1.92, \mathrm{SD}_{\text {pretest }}=1.17\right.$; $\left.M_{\text {posttest }}=1.83, \mathrm{SD}_{\text {posttest }}=0.94\right)$ and fourth graders $\left(M_{\text {pretest }}=2.46, \mathrm{SD}_{\text {pretest }}=0.90\right.$; $\left.M_{\text {posttest }}=2.59, \mathrm{SD}_{\text {posttest }}=0.76\right)$ in the control training group. 
Fig. 1 Proficiency scores on the standardized, normed CITO Reading Comprehension Test presented as a function of training group (control vs. mental simulation) and time (pretest vs. posttest) (+SE) for Grade 3 (upper panel) and Grade 4 (lower panel)
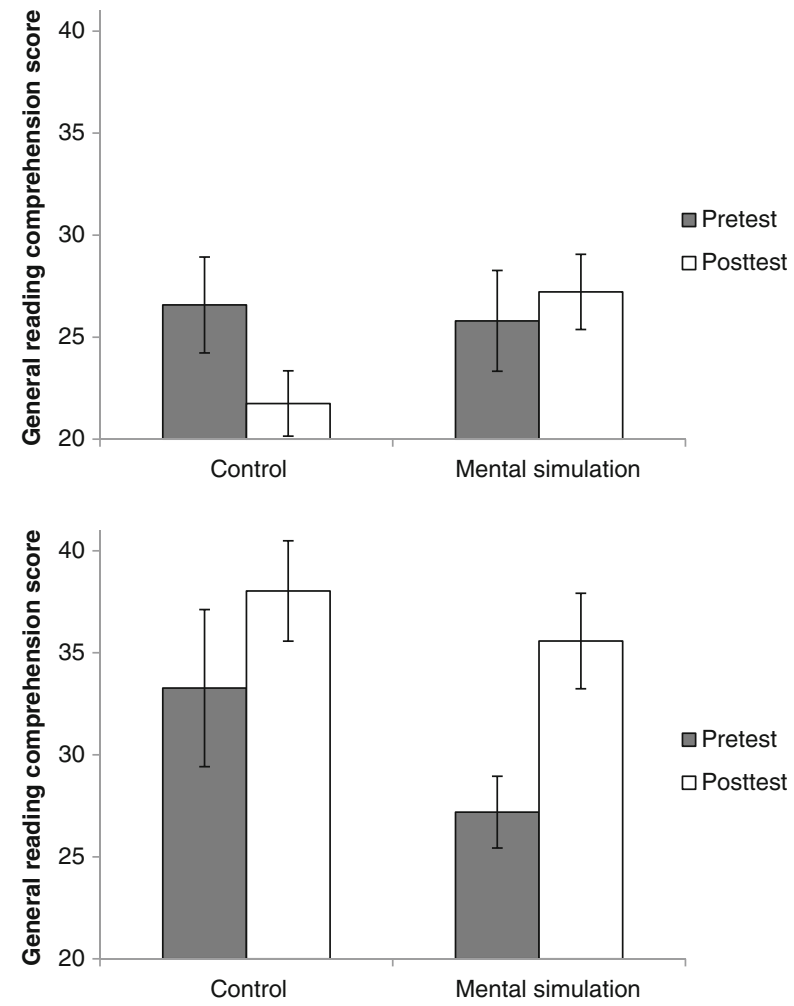

\section{Mental Simulation of Visual and Motor Information}

Analyses of the sentence-picture verification task (SPVT) and the sentence-sensibility judgment task (SSJT) items showed that the average proportion of correct answers to all items was high at pretest $\left(M_{\mathrm{spvt}}=0.96, \mathrm{SD}_{\mathrm{spvt}}=0.05 ; M_{\mathrm{ssjt}}=0.93, \mathrm{SD}_{\mathrm{ssjt}}=0.06\right)$ and at posttest $\left(M_{\mathrm{spvt}}=0.95, \mathrm{SD}_{\mathrm{spvt}}=0.06 ; M_{\mathrm{ssjt}}=0.93, \mathrm{SD}_{\mathrm{ssjt}}=0.06\right)$. This indicates that in both tasks, participants had understood the procedure and were not biased towards negative or affirmative

Fig. 2 Reading motivation score presented as a function of training group (control vs. mental simulation) and time (pretest vs. posttest) (+SE)

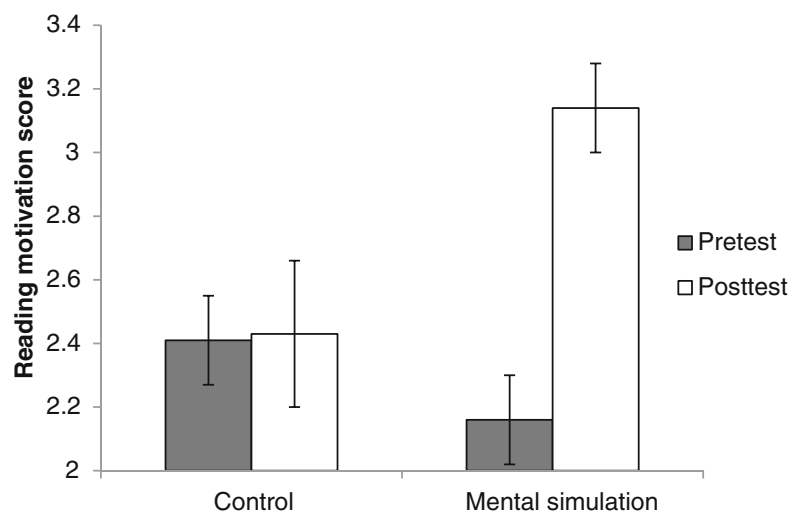


responses. In both tasks, for the response time analyses, filler items were excluded and incorrect responses were eliminated. Outlier analyses in the SPVT and SSJT were conducted based on procedures used in prior studies. In the SPVT response times faster than $300 \mathrm{~ms}$ and slower than $3000 \mathrm{~ms}$ as well as response times which were more than 2.5 standard deviations from participants' mean response time in the match and mismatch conditions were removed (e.g., De Koning et al. 2016; Wassenburg et al. 2015b). In the SSJT, we removed all reading times faster than $50 \mathrm{~ms}$ as well as those more than 2.5 standard deviations from the participants' mean (e.g., Bergen and Wheeler 2010; Gianelli et al. 2011). This resulted in removal of less than 5.0 and $5.6 \%$ of the data in the SPVT and SSJT, respectively. On the remaining response times, for each task, a separate $2 \times 2 \times 2 \times 2$ analysis of variance (ANOVA) was conducted with matching (match vs. mismatch) and time (pretest vs. posttest) as withinsubject variables and training group (mental simulation vs. control) and grade (Grade 3 vs. Grade 4) as the between-subject variables.

Even though the main effect of grade was significant in the SPVT (children from Grade 4 were faster than children from Grade 3 (139 ms on average; $F(1,112)=7.09, p=0.01$, $\eta_{p}{ }^{2}=0.06$ ), but not in the SSJT, none of the other variables interacted significantly with grade (all $p \mathrm{~s}>0.07$ ). Therefore, for reasons of clarity, we decided not to include grade in Figs. 3 and 4. As shown in Fig. 3, there was a significant main effect of matching in the SPVT $\left(F(1,112)=9.04, p=0.00, \eta_{p}{ }^{2}=0.08\right)$, indicating that matching items (where the pictured shape was the same as the shape implied in the sentence) were verified faster than mismatching items (where the pictured shape was not the same as the shape implied in the sentence). Consistent with these results, as displayed in Fig. 4, there was a significant main effect of matching in the $\operatorname{SSJT}\left(F(1,113)=18.34, p<0.001, \eta_{p}{ }^{2}=0.14\right)$. These findings replicated the results of prior studies reporting a match effect in the task for visual simulation (SPVT) (e.g., Engelen et al. 2011; De Koning et al. 2016; Zwaan et al. 2002) and in the task for motor simulation (SSJT) (e.g., Glenberg and Kaschak 2002) and thus reinforced the validity of both tasks, warranting further analyses and interpretation of pre-to-posttest performance.

Regarding pre- and posttest training group differences, the pattern of findings for the sentence-picture verification task and the sentence-sensibility judgment task also appeared to be comparable. As can be seen from respectively Figs. 3 and 4, the mental simulation

Fig. 3 Response times to the pictures (in milliseconds) in the sentence-picture verification task presented as a function of matching condition (match vs. mismatch), training group (control vs. mental simulation), and time (pretest vs. posttest) (+SE)

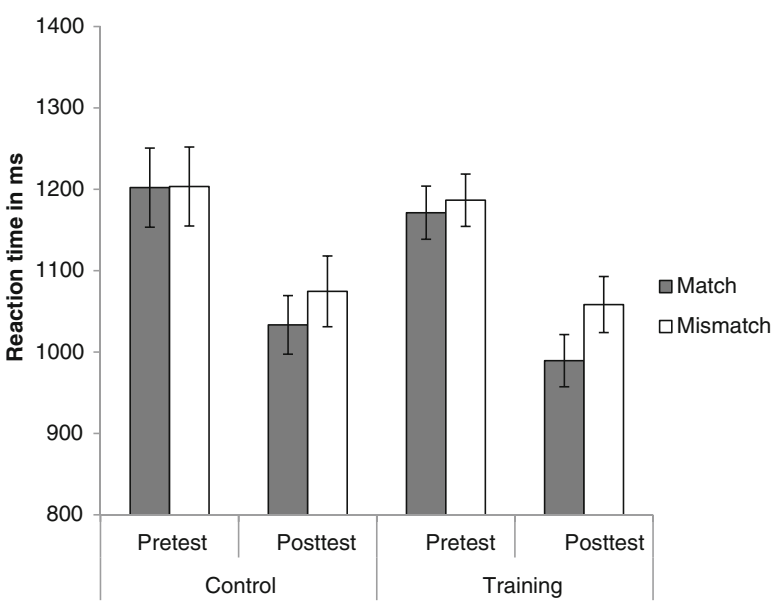


Fig. 4 Reading times (in milliseconds) in the sentencesensibility judgment task presented as a function of matching condition (match vs. mismatch), training group (control vs. mental simulation), and time (pretest vs. posttest) $(+\mathrm{SE})$

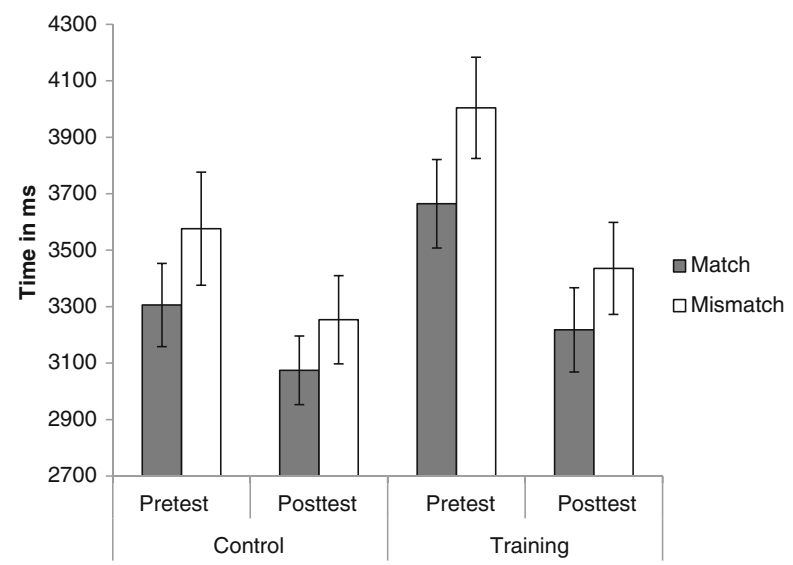

training group and the control training group showed almost identical match effects on the SPVT and SSJT at pretest (matching $\times$ training group $F_{\text {spvt }}(1,119)=0.00, p=0.99$, $\left.\eta_{p}{ }^{2}=0.00 ; F_{\mathrm{ssjt}}(1,121)=1.50, p=0.22, \eta_{p}{ }^{2}=0.01\right)$ and posttest (matching $\times$ training group $F_{\text {spvt }}(1,116)=1.14, p=0.29, \eta_{p}{ }^{2}=0.01 ; F_{\text {ssjt }}(1,115)=0.016, p=0.90$, $\left.\eta_{p}{ }^{2}=0.00\right)$. Obviously, this resulted in a non-significant matching $\times$ training group $\times$ time interaction for both tasks $\left(F_{\text {spvt }}(1,112)=0.44, p=0.506, \eta_{p}{ }^{2}=0.004 ; F_{\text {ssjt }}(1,113)=0.83\right.$, $\left.p=0.36, \eta_{p}{ }^{2}=0.007\right)$. Furthermore, in both tasks, children in the mental simulation training and in the control training experienced an overall pre-to-posttest decrease in response times, presumably because they were more familiar with the task at posttest due to their prior encounter with this task at pretest (time $F_{\text {spvt }}(1,112)=26.87, p<0.001$, $\left.\eta_{p}{ }^{2}=0.19 ; F_{\text {ssjt }}(1,113)=16.61, p<0.001, \eta_{p}{ }^{2}=0.13\right)$.

Another interesting pattern that can be observed in Figs. 3 and 4 is that for both the mental simulation training group and the control training group, the magnitude of the match advantage was larger at posttest than pretest in the SPVT, whereas in the SSJT the match advantage pattern seems to be reversed. To statistically test this suggestion, we conducted a $2 \times 2 \times 2 \times 2 \times 2$ analysis of variance (ANOVA) with time (pretest vs. posttest), matching (match vs. mismatch), and task (SPVT vs. SSJT) as within-subject variables and training group (mental simulation vs. control) and grade (Grade 3 vs. Grade 4) as between-subject variables. This analysis confirmed the observed pattern in a significant matching $\times$ time $\times$ task interaction $\left(F(1,108)=4.73, p=0.03 \eta_{p}{ }^{2}=0.04\right)$. Follow-up analyses showed that on the SSJT, the match advantage tended to be larger at posttest than at pretest (matching $\times$ time $\left.F(1,113)=2.96, p=0.08, \eta_{p}{ }^{2}=0.03\right)$. For the SPVT, overall the match advantage at pretest was statistically comparable to that at posttest (matching $\times$ time $F(1,112)=1.90, p=0.17$, $\eta_{p}{ }^{2}=0.02$ ). It is unclear what may have caused this difference, but one explanation could be that on the SSJT, children's increased familiarity with the task might have made them less susceptible to the interfering influence of the mismatch between the movement direction implied in a sentence and the direction of movement required to give a response, resulting in faster response times on mismatching items. Future studies are warranted to further investigate this speculative explanation.

In sum, the results indicate that after the mental simulation training children did not show evidence of improved visual simulation skills compared to the control training group based on 
their performance on the SPVT. Nor are the results indicative of improved motor simulation skills after the mental simulation training based on children's performance on the SSJT.

\section{Discussion}

This study sought to investigate the effectiveness of a mental simulation training to enhance reading comprehension in children. Essentially, this training focused on encouraging children to connect their sensorimotor experiences to the information in the text they were reading. Both this multisensory approach and the fact that particular attention was devoted to mentally simulating implicitly described visual and motor information provide an advance over prior empirical work (De Koning and van der Schoot 2013). Also, it moves beyond current classroom practices on reading comprehension instruction where reading as a multisensory experience has so far hardly pervaded (De Koning and van der Schoot 2014). Regarding training effectiveness, the mental simulation training provides the following valuable insights.

The main finding of this study is that the mental simulation training improved children's general reading comprehension performance. Specifically, in the mental simulation training, third-grade (but not fourth-grade) children showed a larger pretest-to-posttest improvement on our standardized test of general reading comprehension than children in the control training. Given that the time for completing the standardized reading comprehension test was restricted, it is unlikely that third graders' improved performance in the mental simulation group is simply the result of taking longer to read and try to comprehend the stories contained in the posttest. Rather, considering the activities the training actually encompassed, this finding suggests that it seems important that reading comprehension instruction in third grade involves children's sensory and motor experiences during reading in an attempt to build an "embodied" situation model. Our study demonstrates that the aggregate of instructions and exercises encouraging these children to (1) connect the text to their sensorimotor experiences and memories to "experience" the text information as vividly as possible and (2) engage in visual and motor simulations of implicitly described information improve reading comprehension performance. It remains to be explored in future research to what extent each of the above-mentioned components of the mental simulation training individually contributes to improved reading comprehension. Also, it is yet unclear why the mental simulation training was more effective for children in Grade 3 than for children in Grade 4. Possibly, such a mental simulation training is only effective when initial reading skills are relatively poor and children have not yet mastered other reading comprehension strategies that they can rely on. Future research is warranted to further investigate this. Moreover, it would be useful for future studies to consider the extent to which procedural aspects of the mental simulation training have contributed to the improved performance in the mental simulation training group. Even though we have tried to do what was within our limits to match the experimental and control trainings on all possible aspects, presumably some differences still remained. For example, we did not have control over what actually happened in the control training both regarding the amount of time spent on discussing the taught reading comprehension strategies and whether teachers brought sufficient depth into the discussion. It is possible that children in the experimental training group spent more time on talking about reading and strategy use, or did this in more depth, than children in the control group. Trying to get a grip on such issues is a challenge that should be taken on in future research. 
Interestingly, the improved reading comprehension performance of (third-grade) children in the mental simulation training was accompanied by increased levels of reading motivation. Compared to children in the control training group, children who had received the mental simulation training indicated that they liked reading comprehension more after the training. This finding is consistent with prior research showing that being able to build a vivid mental representation from text, which we tried to stimulate in the present study, positively influences children's reading motivation in general (Retelsdorf et al. 2011; Taboada et al. 2009). Nevertheless, it is worth mentioning that the improved motivation in the mental simulation training group also could, at least partially, be related to the fact that for the mental simulation training research assistants performed the instructions, whereas for the control training group the instructions were performed by the children's regular teachers. It is conceivable that children found it more motivating to receive instruction from a person different than their own classroom teacher. Future studies could help to clarify whether this actually is a valid explanation. Additionally, it should be stressed that our reading motivation results only provide the first exploratory insight into whether a non-linguistic multisensory reading approach as investigated in this study would increase reading motivation. It is not possible to give more fine-grained information on the various aspects of reading motivation based on our one-item, four-point Likert scale measure (Wigfield and Guthrie 1997). We therefore recommend future studies to use a more elaborate questionnaire to investigate effects of reading comprehension strategy trainings, like the one described in this study, on reading motivation more thoroughly.

An unexpected result was that we failed to find direct evidence of improved visual and motor simulation skills due to the mental simulation training. That is, after the training, children in the mental simulation training did not show a stronger match advantage on the SPVT and SSJT than children in the control training. A possible explanation for this could be that taking (a different version of) the same mental simulation tasks both at pre- and posttest simply overshadowed the subtle millisecond differences that one might expect in these tasks. So far, it is unknown whether and if so how the match advantage in these mental simulation tasks is influenced by repeated encounters with such tasks (e.g., SPVT-SPVT; SPVT-SSJT); in prior research, the focus typically is on only one of these tasks and participants perform a visual simulation or motor simulation task just once (Horchak et al. 2014). Our findings provide a first step in exploring this issue and through this extend existing research on mental simulation during reading in a novel direction.

In an attempt to further explain these findings, it is important to realize that "mental simulation" is a multifaceted concept of which the mental simulation tasks used in this study only capture a specific aspect (e.g., Horchak et al. 2014). Additionally, these mental simulation tasks are constrained in the sense that they require a speeded response on short sentences that all have a comparable structure. For example, sentences in these tasks are of the format "subject-verb-noun-location" (e.g., SPVT: The man saw the eagle in the sky; SSJT: He put the newspaper in the mailbox). A potential risk of such a repeating sentence structure is that children strategically process the sentences, for example by only directing attention to critical words instead of reading naturalistically (Wassenburg et al. 2015a). This would suggest that our mental simulation tasks simply could not accurately detect the expected mental simulation processing. We cannot exclude the possibility that our mental simulation training has contributed to such a strategic processing approach. Although we emphasized that all words in the sentences were relevant for constructing a mental simulation of implied textual information, except for the final training lesson, there was always just one to-be-simulated concept or movement "hidden" in each practice and test sentence. 
In contrast to the mental simulation tasks, the texts in the general reading comprehension test were longer narratives which offered readers a more naturalistic reading experience with ample opportunities to mentally simulate the different concepts, situations, movements, and scenarios described in the text. That is, sentences in these texts included both explicit and implicit descriptions and substantially varied in structure and the number of concepts they contained. This required children to actively search for words and phrases which they can connect to their sensory and motor experiences to mentally simulate what is described. In doing so, the children presumably relied on all of the trained aspects (i.e., involving all senses, simulate implied visual and motor information) to mentally simulate the text information. Consistent with how mental simulation was trained, this likely occurred to a large extent by deliberately constructing a mental simulation of what was described in the text. Although the training attempted to stimulate children to internalize the learned mental simulation skills, this was restricted to requiring children to practice with different types of mental simulation exercises intermixed in the last two lessons. For the performance on the standardized general reading comprehension test, this did not provide an obstacle as the test allowed children to read at their own pace and did not demand a fast response. For the mental simulation tasks, however, children had to provide a speeded response which likely reflects the extent to which the learned mental simulation skills have been automatized (Moulton and Kosslyn 2009). This would be consistent with prior research showing that these types of mental simulation tasks effectively capture routinely simulated text information (e.g., Horchak et al. 2014). According to this interpretation, children in the mental simulation training might not have adequately internalized the mental simulation skills and hence did not show improved performance on the mental simulation tasks. Presumably, this is partly due to the limited number of lessons and attention devoted to this aspect in the mental simulation training. Future research is warranted to investigate this issue as well as the above explanations in more detail.

In conclusion, the current study demonstrates that it is possible to develop an effective intervention aimed at promoting reading comprehension in primary school which is based on recent insights from fundamental mental simulation research. Importantly, our findings suggest that for third-grade children, it is important to move beyond common practice of simply teaching reading strategies focusing readers' attention on text-based processing like questioning and summarizing and draw more on readers' multisensory and situational experiences during reading comprehension lessons (De Koning and van der Schoot 2013). Rather than just supporting readers to "see" the described situation visually in their mind, it is important to stimulate them to mentally experience explicitly described or implied text information based on reinstatements of sensorimotor experiences. This enables readers to also "feel," "hear," "smell," and "act out" the described situation as if they were actually experiencing it. More research is definitely needed to further develop and refine such a multisensory reading approach. The present study not only serves as a useful starting point from which future endeavors can be explored, it also demonstrates that this would provide a valuable addition to reading comprehension instruction.

Acknowledgments This research was supported by a grant from the Netherlands Organization for Scientific Research /Dutch Program Council for Educational Research (NWO/PROO) for the project "Learning to read with imagination" (\#411-11-807). We would like to thank Marcella van Beusekom and Rianne den Ouden for their assistance with data collection. We also thank CITO for providing us with information on the standardized reading comprehension tests and assisting in the assessment and scoring procedures. 
Open Access This article is distributed under the terms of the Creative Commons Attribution 4.0 International License (http://creativecommons.org/licenses/by/4.0/), which permits unrestricted use, distribution, and reproduction in any medium, provided you give appropriate credit to the original author(s) and the source, provide a link to the Creative Commons license, and indicate if changes were made.

\section{References}

Barsalou, L. W. (1999). Perceptual symbol systems. Behavioral and Brain Sciences, 22, 577-660.

Barsalou, L. W. (2008). Grounded cognition. Annual Review of Psychology, 59, 617-645. doi:10.1146/annurev. psych.59.103006.093639.

Berenhaus, M., Oakhill, J., \& Rusted, J. (2015). When kids act out: a comparison of embodied methods to improve children's memory for a story. Journal of Research in Reading, 38, 331-343. doi:10.1111/14679817.12039.

Bergen, B., \& Wheeler, K. (2010). Grammatical aspect and mental simulation. Brain \& Language, 112, 150-158. doi:10.1016/j.band1.2009.07.002.

Bos, L. T., De Koning, B. B., Wassenburg, S. I., \& van der Schoot, M. (2016). Training inference making skills using a situation model approach improves reading comprehension. Frontiers in Psychology: Educational Psychology, 7:116. doi:10.3389/fpsyg.2016.00116.

Brus, B. T., \& Voeten, M. J. M. (1999). Een-minuut-test: Vorm A en B: Verantwoording en handleiding: Schoolvorderingentest voor de technische leesvaardigheid, bestemd voor groep 4 tot en met 8 van het basisonderwijs [One-minute-test: Version A and B. Justification and manual: Test for progress at school regarding decoding skill, from Grade 4 through Grade 8 of primary school]. Lisse: Swets \& Zeitlinger.

De Koning, B. B., \& van der Schoot, M. (2013). Becoming part of the story! Refueling the interest in visualization strategies for reading comprehension. Educational Psychology Review, 25, 261-287. doi:10.1007/s10648-013-9222-6.

De Koning, B. B., \& van der Schoot, M. (2014). "Hoe zie jij het voor je?” Een kritische blik op de hedendaagse onderwijspraktijk van begrijpend lezen. Pedagogische Studiën, 91, 422-430.

De Koning, B. B., Wassenburg, S. I., Bos, L. T., \& van der Schoot, M. (2016). Size does matter: Implied object size is mentally simulated during language comprehension. Discourse processes, in press.

Engelen, J. A. A., Bouwmeester, S., de Bruin, A. B. H., \& Zwaan, R. A. (2011). Perceptual simulation in developing language comprehension. Journal of Experimental Child Psychology, 110, 659-675. doi:10.1016/j.jecp.2011.06.009.

Feenstra, H., Kamphuis, F., Kleintjes, F., \& Krom, R. (2010). Begrijpend lezen voor groep 3 tot en met 6. Wetenschappelijke verantwoording [Reading comprehension for Grade 1 to 4. Scientific report]. Arnhem: Cito.

Fischer, M. H., \& Zwaan, R. A. (2008). The role of the motor system in language comprehension. Quarterly Journal of Experimental Psychology, 61, 825-850. doi:10.1080/17470210701623605.

Gianelli, C., Farne, A., Salemme, R., Jeannerod, M., \& Roy, A. C. (2011). The agent is right: when motor embodied cognition is space-dependent. PLoS One, 6(9), e25036. doi:10.1371/journal.pone.0025036.

Glenberg, A. M. (1997). What memory is for. The Behavioral and Brain Sciences, 20, 1-55.

Glenberg, A. (1999). Why mental models must be embodied. In G. Rickheit \& C. Habel (Eds.), Mental models in discourse processing and reasoning (pp. 77-90). Amsterdam: North-Holland/Elsevier Science Publishers.

Glenberg, A. M. (2011). How reading comprehension is embodied and why that matters. International Electronic Journal of Elementary Education, 4, 5-18.

Glenberg, A. M., \& Kaschak, M. P. (2002). Grounding language in action. Psychonomic Bulletin and Review, 9, 558-565. doi:10.3758/BF03196313.

Glenberg, A. M., Gutierrez, T., Levin, J. R., Japuntich, S., \& Kaschak, M. P. (2004). Activity and imagined activity can enhance young children's reading comprehension. Journal of Educational Psychology, 96, 424 436. doi:10.1037/0022-0663.96.3.424.

Guthrie, J. T., Taboada, A., \& Coddington, C. S. (2007). Engagement practices for strategy learning in ConceptOriented Reading Instruction. In D. S. McNamara (Ed.), Reading comprehension strategies: Theory, interventions, and technologies (pp. 241-266). Mahwah: Erlbaum.

Horchak, O. V., Giger, J., Cabral, M., \& Pochwatko, G. (2014). From demonstration to theory in embodied language comprehension: a review. Cognitive Systems Research, 29(30), 66-85. doi:10.1016/j. cogsys.2013.09.002.

Houtveen, A. A. M., \& van de Grift, W. J. C. M. (2007). Effects of metacognitive strategy instruction and instruction time on reading comprehension. School Effectiveness and School Improvement, 18, 173-190. doi:10.1080/09243450601058717. 
Institute for Educational Measurement (2010). Leerling-en Onderwijsvolgsysteem, Begrijpend Lezen [Reading Comprehension Test]. Arnhem: Cito.

Kent, C., \& Lamberts, K. (2008). The encoding-retrieval relationship: retrieval as mental simulation. Trends in Cognitive Science, 12, 92-98. doi:10.1016/j.tics.2007.12.004.

Kiefer, M., \& Pulvermüller, F. (2012). Conceptual representations in mind and brain: theoretical developments, current evidence and future directions. Cortex, 48, 805-825. doi:10.1016/j.cortex.2011.04.006.

Kintsch, W. (1988). The role of knowledge in discourse comprehension: a construction integration model. Psychological Review, 95, 163-182. doi:10.1037/0033-295X.95.2.163.

Kintsch, W., \& Van Dijk, T. A. (1978). Toward a model of text comprehension and production. Psychological Review, 85, 363-394. doi:10.1037/0033-295X.85.5.363.

Knol, F., Boelhouwer, J., \& Veldheer, V. (2012). Statusontwikkeling van wijken in Nederland 1998-2010. Den Haag: Sociaal en Cultureel planbureau.

Louwerse, M. M., Hutchinson, S., Tillman, R., \& Recchia, G. (2015). Effect size matters: the role of language statistics and perceptual simulation in conceptual processing. Language, Cognition and Neuroscience, 30, 430-447. doi:10.1080/23273798.2014.981552.

Meteyard, L., Cuadrado, S. R., Bahrami, B., \& Vigliocco, G. (2012). Coming of age: a review of embodiment and the neuroscience of semantics. Cortex, 48, 788-804. doi:10.1016/j.cortex.2010.11.002.

Morgan, P. L., \& Fuchs, D. (2007). Is there a bidirectional relationship between children's reading skills and reading motivation? Exceptional Children, 73, 165-183. doi:10.1177/001440290707300203.

Moulton, S. T., \& Kosslyn, S. M. (2009). Imagining predictions: mental imagery as mental emulation. Philosophical Transactions of the Royal Society B, 364, 1273-1280. doi:10.1098/rstb.2008.0314.

National Center for Education Statistics (2011). The Nation's Report Card: Reading 2011 (NCES 2012-457). Washinton, DC: Institute of Education Sciences, U.S. Department of Education.

Nijhof, A. D., \& Willems, R. M. (2015). Simulating fiction: individual differences in literature comprehension revealed with fMRI. PLoS One, 10, e0116492. doi:10.1371/journal.pone.0116492.

Retelsdorf, J., Köller, O., \& Möller, J. (2011). On the effects of motivation on reading performance growth in secondary school. Learning and Instruction, 21, 550-559. doi:10.1016/j.learninstruc.2010.11.001.

Taboada, A., Tonks, S., Wigfield, A., \& Guthrie, J. (2009). Effects of motivational and cognitive variables on reading comprehension. Reading and Writing: An Interdisciplinary Journal, 22, 86-106. doi:10.1007 /s11145-008-9133-y.

Trumpp, N. M., Traub, F., \& Kiefer, M. (2013). Masked priming of conceptual features reveals differential brain activation during unconscious access to conceptual action and sound information. PLoS ONE, 8, e65910.

Trumpp, N. M., Traub, F., Pulvermuller, F., \& Kiefer, M. (2014). Unconscious automatic brain activation of acoustic and action-related conceptual features during masked repetition priming. Journal of Cognitive Neuroscience, 26, 352-364. doi:10.1162/jocn_a_00473.

van Berkel, S., Krom, R., Heesters, K., van der Schoot, F., \& Hemker, B. (2007). Balans van het leesonderwijs halverwege de basisschool [Assessing performance in reading halfway primary school]. Arnhem: Cito.

van de Ven, A. H. F. M. (2009). Actief lezen: zie, voel en (be)grijp de tekst. Het belang van het oproepen van mentale beelden en zintuiglijke gewaarwordingen bij tekstbegrip. Tijdschrift voor Orthopedagogiek, 48, $451-461$.

van der Schoot, F. (2008). Onderwijs op peil? Een samenvattend overzicht van 20 jaar PPON [A summary overview of 20 years of national assessments of the level of education]. Arnhem: Cito.

Van Sluys, K. E. (2008). Engaging as ethnographers: Insights from the collaborative study of a literacy learning community. Voices from the Middle, 16, 15-22.

Wassenburg, S. I., Bos, L. T., De Koning, B. B., \& van der Schoot, M. (2015a). Effects of an inconsistencydetection training aimed at improving comprehension monitoring in primary school children. Discourse Processes, 52, 463-488. doi:10.1080/0163853X.2015.1025203.

Wassenburg, S. I., De Koning, B. B., de Vries, M., Boonstra, A. M., \& van der Schoot, M. (2015b). Gender differences in mental simulation during sentence and word processing. Journal of Research in Reading. doi:10.1111/1467-9817.12066.

Wigfield, A., \& Guthrie, J. T. (1997). Relations of children' motivation for reading to the amount and breadth or their reading. Journal of Educational Psychology, 89, 420-432. doi:10.1037/0022-0663.89.3.420.

Zwaan, R. A. (2004). The immersed experiencer: toward an embodied theory of language comprehension. In: B.H. Ross (Ed.), The Psychology of Learning and Motivation, Vol. 44 (pp. 35-62). New York: Academic Press.

Zwaan, R. A. (2015). Situation models, mental simulations, and abstract concepts in discourse comprehension. Psychonomic Bulletin \& Review. doi:10.3758/s13423-015-0864-x.

Zwaan, R. A., \& Pecher, D. (2012). Revisiting mental simulation in language comprehension: six replication attempts. PLoS One, 7(12), e51382. doi:10.1371/journal.pone.0051382. 
Zwaan, R. A., \& Radvansky, G. A. (1998). Situation models in language comprehensio and memory. Psychological Bulletin, 123, 162-185. doi:10.1037/0033-2909.123.2.162.

Zwaan, R. A., Langston, M. C., \& Graesser, A. C. (1995). The construction of situation models in narrative comprehension: an event-indexing model. Psychological Science, 6, 292-297. doi:10.1111/j.14679280.1995.tb00513.x.

Zwaan, R. A., Stanfield, R. A., \& Yaxley, R. H. (2002). Language comprehenders mentally represent the shapes of objects. Psychological Science, 13, 168-171. doi:10.1111/1467-9280.00430. 